\title{
Heterogeneity, Diversity, and Complementarity in Alliance Portfolios
}

\begin{abstract}
:
The divergence that a firm manages to achieve because of its partners is a fundamental question in an alliance portfolio configuration. Diversity can refer not only to the differences between the focal firm and its partners or between the partners themselves but also to the differences arising from various resource endowments in the alliance portfolio. Understanding the significance of these different sources, how they interrelate, and how they affect the firm performance is an unresolved question as unclear definitions and opposing arguments are proposed. This paper expounds the concepts of partner heterogeneity, alliance portfolio diversity, and network resource complementarity to gain a deeper comprehension of the alliance portfolio configuration and how it affects performance. Our analysis of airline alliances at a global level reveals the central role of resource complementarity in the focal firm performance.
\end{abstract}

\section{Keywords:}

Heterogeneity, Diversity, Complementary, Alliance Portfolio, Network Resources. 


\section{Introduction}

Strategic alliances play a vital role in firm survival as long as they contribute external resources that allow firms to gain and maintain competitive advantages $(\mathrm{Mu}$, Love \& Peng, 2008). These external resources are referred to as network resources (Gulati, 2007). Access to them and their eventual use is a key motivation for the company to involve itself in interorganizational ties and alliance formation.

In very competitive and highly fluctuating business environments, some organizations usually enter into multiple agreements with other firms to develop various competitive advantages simultaneously. The set of firm alliances is referred to as its alliance portfolio, and it generates a need for global and simultaneous management of all alliances so that the company achieves its objectives (Wassmer, 2010). Hoffmann (2007: 834) stated that alliance portfolio compositions "determine the quality, quantity, and diversity of information and resources to which the focal company has access." In other words, the global firm's network resource access will be determined by who its partners are (in different alliances) and by those partners' resources.

Previous literature about Network Theory and Resource-based view has highlighted that network resources to which a company has access through its relations should be complemented and/or combined with its own resources (Chung, Singh \& Lee, 2000; Eisenhardt \& Schoonhoven, 1996; Lavie, 2006; Mitsuhashi \& Greve, 2009; Stuart, 2000; Wassmer, 2007; Zheng, Li \& Wu, 2013). Therefore, it is relevant to find partners that are different from the focal firm and partners with resources that differ from its own resources.

Baum, Calabrese and Silverman (2000) previously indicated the need to configure alliance portfolios, within their classic conceptualization, to permit access to more divergent information and capabilities. Diversity, nonredundancy, synergy, and the breadth of partner resource characteristics are relevant elements connected to the company's performance that form part of the research agenda on alliance portfolio configuration (Wassmer, 2010). In the recent literature, even greater interest has been expressed in evidence that shows how different aspects of the alliance portfolio configuration (particularly diversity and/or similarity between firms and between the resources that they own) affect company performance (Collins \& Riley, 2013; Cui \& O'Connor, 2012; De Leew, Lokshin, \& Duysters, 2014; Duysters \& Lokshin, 2011; Kim, 2014; Lavie, 2007; Sarkar, Aulakh, \& Madhok, 2009).

However, at a conceptual level, there is still a lack of clarity over the use of different words, and there are levels of analysis that describe the circumstances in which an alliance portfolio configuration improves performance. Words such as heterogeneity, diversity, or complementarity are used abundantly to refer to different situations and levels. On occasions, the different terms appear mixed up with the same definition: "Alliance partner heterogeneity refers to the breadth or diversity of the complementary capabilities held by different alliance participants" (Lin, 2012) and "Diversity refers to the heterogeneity of resources or knowledge and thus yields the potential for novel combinations to emerge" (Vanhaverbeke, Gilsing, Beerkens, \& Duysters, 2009). Therefore, there is a need to clarify the concepts that are used in the previous literature before referring to the alliance portfolio diversity.

Although the different sources can be broader and can refer to structural questions and to both geographic and cultural distances (Ahuja, Polidoro \& Mitchell, 2009; Lavie $\&$ Miller, 2008), the previous literature has indicated that the basic divergence sources focus on the differences between both partners and resources (Gulati, Lavie \& Madhavan, 2011; Kale \& Singh, 2009). The differences between the alliance portfolio 
partners may arise between them or with the focal firm. Following previous papers on network approach strategy, this work centers on the different sources that, in a direct way, are linked to the network resources and understand network resource as partner resource endowment (Lavie, 2008).

Earlier research has noted firm heterogeneity as a preliminary factor in the existence of complementarity, and both concepts are linked to business performance (Baum et al., 2000; Burt, 1992; Lavie, 2006; Mitsuhashi \& Greve, 2009; Wassmer, 2007). Other studies indicate the way in which company homogeneity stimulates innovation and improves results (Ahuja, 2000; Cui \& O'Connor, 2012). Therefore, there is a certain controversy about what the best type of partner might be to improve the business performance. Previous studies have proposed arguments and evidence that indicate that holding a more diverse alliance portfolio and one contributing complementary resources yields positive or negative results or results that change over time. There are no reviews that discuss the different forms of differences that can arise in an alliance portfolio and how these forms are interrelated with each other (e.g., if some may be the antecedents or consequences of others). Therefore, there is a gap in the literature that covers the various ways of considering divergence or convergence in the alliance portfolio configuration, the possible connections between them, and how differences affect firm performance in different ways.

The aim of this work is to look more deeply at the question of the alliance portfolio configuration following the lines marked out by Hoffmann (2007) and Wassmer (2010). The objective is to contribute to a better understanding of the relations between the three basic forms of understanding the differences in alliance portfolio configuration (heterogeneity between the focal firm and its partners, diversity between the partners, and resource complementarity) and how these (each one separately and in relation to each other) affect the business performance. Therefore, this work will seek to specify whether they are related in either a positive or a negative way to the results (or in a nonlinear way) and whether they do so directly or indirectly. Moreover, this paper defines these three forms of difference in an alliance portfolio.

Codeshare alliances shared between airlines at an international level have been considered for this purpose, employing data from 135 alliance portfolios that include the main companies in the sector and represent over $70 \%$ of the total.

\section{Theoretical Review}

The problem of how the focal firm selects more or less different partners is a key in the study of alliance portfolios (Castro, Casanueva \& Galán, 2014). The variety of partners and the divergence of the resources that they contribute are decisive for the alliance portfolio configuration (Hoffmann, 2007).

However, the following key questions surround what we consider a different partner. How do we analyze the differences? What is the basis of those differences? Placing the focus on network resources (Gulati, 2007; Lavie, 2008), alliance portfolio divergence has been considered in numerous previous studies. A review of the literature shows that an unresolved conceptual problem exists over the name of each concept (see Appendix).

In this research, three differentiated concepts are proposed to analyze divergence and convergence within an alliance portfolio: heterogeneity, portfolio diversity, and complementarity. We considered that heterogeneity refers to "how different the organization is from its partners" (Gulati et al., 2011), diversity is "the extent of variance in a focal firm's alliance partners" (Collins \& Riley, 2013), and 
complementarity is "the extent to which a partner contributes non-overlapping resources to the relationship" (Kale \& Singh, 2009).

Business networks have to be considered at two levels. The first is the dyadic level that relates the focal firm with each one of its partners and proposes whether they are different because of their characteristics or because of their resource endowment. The second is at the egonet level-alliance portfolio. At this level, the differences between the focal firm egonet members are considered: between their partners. A distinction should be made between whether the differences refer to the firm characteristics or to their resource endowment.

Table 1 sets out a conceptual framework with which to analyze the difference in the alliance portfolio, which considers three sources of divergence: differences between the characteristics of either the firms or the resources and the consideration of two network levels (dyad and egonet). Each new partner choice in the alliance portfolio configuration is a commitment and has an effect at the dyadic level (specific alliance with the new partner) and at the global or network level as long as it shapes and modifies the egonet characteristics and structure (alliance portfolio).

In Table 1, heterogeneity is linked to the existence of different attributes between two partners. It is a similar concept to the one used by Gulati et al. (2011), where they refer to differences between the firms' characteristics that create an alliance and the Parkhe's (1991) type II diversity. Therefore, heterogeneity focuses on the differences between dyadic pairs (focal company and each of their partners' characteristics, one by one). Diversity centers on the ego network: all focal firm partners without the focal firm itself. In this way, the differences between the alliance portfolio members are considered, without considering focal organization characteristics. This definition of diversity is similar to those given by Collins and Riley (2013) and Jiang, Tao and Santoro (2010). Finally, complementarity refers to the comparison of the resource endowments (and the nature of those resources) between the focal firm and its partners. Complementarity refers to finding the resources that the focal firm needs in another firm when they find the ideal combination and their effect is greater together than it is individually (Gulati, 1999). If both the partners' resources are similar, then those resources will be redundant (Huggins, 2010).

With regard to the relations between these three divergence sources (partner heterogeneity, alliance portfolio diversity, and network resource complementarity), previous literature has sometimes resorted to one of those relations as a proxy for the other; at other times, these relations have coincided with each other and the results have had variable effects. Thus, some studies have considered heterogeneity as a synonym of diversity (Beckman \& Haunschild, 2002; De Leeuw et al., 2014; Duysters \& Lokshin, 2011). In other studies, there is no clear separation between diversity and heterogeneity (Collins \& Riley, 2013; Jiang et al., 2010). Various studies have linked complementarity to creating alliances with heterogeneous partners, which contribute to the minimization of the overlapping (Abuzaid, 2014; Chung et al., 2000; Duysters \& Lokshin, 2011; Kale \& Singh, 2009; Kim, 2014; Shan \& Hamilton, 1991). Therefore, it is necessary to understand how each alliance portfolio divergence source (separately and combination with the others) affects firm performance.

Table 1: Alliance portfolio divergence sources

\begin{tabular}{|l|l|l|l|}
\hline & $\begin{array}{l}\text { Partner } \\
\text { Heterogeneity/Homogeneity }\end{array}$ & $\begin{array}{l}\text { Alliance Portfolio } \\
\text { Diversity/Similarity }\end{array}$ & $\begin{array}{l}\text { Network Resource } \\
\text { Complementarity/Redundancy }\end{array}$ \\
\hline $\begin{array}{l}\text { Network } \\
\text { level }\end{array}$ & Dyad & Egonet & Dyad \\
\hline Object of & Firms & Firms & Firm resources \\
\hline
\end{tabular}




\begin{tabular}{|l|l|l|l|}
\hline $\begin{array}{l}\text { the } \\
\text { difference }\end{array}$ & Focal firm characteristics vs. \\
\hline $\begin{array}{l}\text { Object of } \\
\text { comparison } \\
\text { partner characteristics }\end{array}$ & $\begin{array}{l}\text { Differences between } \\
\text { all partner } \\
\text { characteristics, } \\
\text { without including the } \\
\text { focal firm }\end{array}$ & $\begin{array}{l}\text { Focal firm resources vs. } \\
\text { partners' resources }\end{array}$ \\
\hline
\end{tabular}

\subsection{Partner heterogeneity and performance}

Heterogeneity means that the focal company characteristics have to be compared with each one of their alliance portfolio partners. The main argument that links heterogeneity to performance is directly linked to resources. Previous works have defined heterogeneity in opposition to homogeneity and have argued that the most valuable firms are companies that have heterogeneous partners as those organizations are more efficient and contribute different resources that encourage the competitive advantages development (Ahuja et al., 2009; Baum et al., 2000; Beckman \& Haunschild, 2002; Lee, 2007; Parkhe, 1991; Wuyts, Dutta \& Stremersch, 2004). In other words, a company must have allies that bring in new resources-different from those that it already has - to improve its performance (Baum et al., 2000; Burt, 1992; Gulati et al., 2011; Mitsuhashi \& Greve, 2009; Reagan \& Zuckerman, 2008).

Another important argument on how heterogeneity favors the alliance performance centers on the difficulty of cooperation between peers. An alliance with direct competitors implies that they are homogenous to focal firm, which can provoke numerous conflicts as they collide in the pursuit of their aims that erode the relationship (Baum et al., 2000; Caner \& Tyler, 2013; De Leeuw et al., 2014; Gomes-Casseres, 1994; Lavie, 2006; Park, Srivastava \& Gnyawali, 2014) and generate opportunistic behavior (Gulati, Nohria, \& Zaheer, 2000). Hitt, Hoskisson and Kim (2001) identified that homogeneous firms are not able to exploit all the alliance opportunities.

It seems that heterogeneous collaborations are more valuable owing to their enlarged range of available resources and what that implies: more flexibility to adapt to environment changes because of different competitive advantages created through combinations of very different resources. These combinations are also almost inimitable because of the combination uniqueness, and in the last instance, they could, according to Dyer (1996), increase their productivity.

However, there are also theoretical arguments and evidence in the literature that show that firm heterogeneity can have a negative effect on performance and is linked to an increase in the costs. Heterogeneity involves a high cost too because a company has to invest more resources to overcome the differences, and these costs reduce the alliance performance (Baum et al., 2000; Collins \& Riley, 2013; De Leeuw et al., 2014).

Despite the above, it seems that the type of partner that prompts better performance will depend on the type of resources that the focal firm wishes to obtain. Grant and Baden-Fuller (2004) showed that if the wish is to access physical or tangible resources, such as markets (Kogut, 1988), the best option will be to associate with heterogeneous partners as the alliance partner produces a pooling of resources that will generate multiple benefits; thus, the focal firm expands into various markets. On the contrary, if the idea is to improve the value chain or to innovate, the best approach is to choose homogenous partners, contacts that will cause cospecialization in the company and a convergence process (Grant \& Baden-Fuller, 2004; Jiang et al., 2010; Park et al., 2014), because convergent firms learn in more effective ways (Lane \& Lubatkin, 1998; Rogers, 1995) and are better at the cocreation processes (Park et al., 2014). 
Thus, there are arguments that point to both a positive and negative relation between partner heterogeneity and focal firm performance; even a nonlinear relation between heterogeneity and performance is possible. Therefore, a better understanding is required about the type of relation that appears between these variables without proposing the relation sign a priori. Accordingly, we may establish the following hypothesis:

\section{H1: Alliance partner heterogeneity is related to the focal firm performance.}

\subsection{Alliance portfolio diversity and performance}

Alliance portfolio diversity compares focal firm partners with each other (their similarities and differences without taking the focal firm into account). In an egonet analysis, diversity is the variety of the partners that participate in the alliance portfolio. Reversely, similarity implies all portfolio partners fit in the same profile.

The motives that drive the alliance portfolio creation usually focus on obtaining network resources because they help create different competitive advantages, react better to environmental changes (Dess, Rasheed, McLaughlin, \& Priem, 1995; Duysters, De Man, \& Wildeman, 1999; Lahiri \& Narayanan, 2013), to innovate (Golonka, 2015), and reduce costs (Bettis, Bradley \& Hamel, 1992; Lahiri \& Narayanan, 2013). Therefore, it would be logical to think that owning multiple partners that contribute very varied resources between each other will increase the possibilities for different and original competitive advantages development. These competitive advantages will be based on combinations that competitors are unable to imitate (Beckman \& Haunschild, 2002; Collins \& Riley, 2013; Duysters, Heimeriks, Lokshin, Meijer \& Sabidussi, 2012; Faems, De Visser, Andries \& Van Looy, 2010; Hoffman, 2007; Jiang et al., 2010; Kim, 2014; Lahiri \& Narayanan, 2013).

The level of alliance portfolio diversity has caused certain researchers concern because a high level of diversity can imply high costs (De Leeuw et al., 2014; Duysters \& Lokshin, 2011; Faems et al., 2010; Lahiri \& Narayanan, 2013; Park et al., 2014) and great effort in alliance coordination and in decisions about portfolio configuration to avoid conflicts and incompatibilities (Collins \& Riley, 2013). Some studies show that alliance portfolio diversity is only positive up to a certain point (Duysters \& Lokshin, 2011; Koka \& Prescott, 2002). Nevertheless, if they overcome the difficulties, for example, with a special alliance function dedicated to coordinate and to facilitate resource exchanges (Dyer, Kale \& Singh, 2001; Faems et al., 2010; Kale, Dyer \& Singh, 2002), firms will share various resources, and those assets will, in turn, give them strategic flexibility to get a better market position and will also increase their survival, allowing them to obtain better performance (Collins \& Riley, 2013; Hamel, Doz \& Prahalad, 1989).

Once again, as with heterogeneity, previous studies advanced both evidence and arguments that indicate the positive relation between alliance portfolio diversity and focal firm performance, whereas others showed that diversity is only positive up to a certain level or that it can be negative. Therefore, our hypothesis suggests the relation between both variables without presupposing the relation sign:

\section{H2: Alliance portfolio diversity will be related to focal firm performance.}

\subsection{Network resources complementarity and performance}

Most of the alliance portfolio configuration has focused on the differences between firms. However, on many occasions, the essential argument was the resource search that they do not own. Complementarity refers to the differences between focal firm 
resources and their partner assets. In other words, complementarity refers to partners with a resource endowment that focal firm does not possess that are nonoverlapping and synergic with those that it does own. Synergy implies that two resources are complementary when their joint performance, which they generate together, is greater than each one by itself (Milgrom \& Roberts, 1990).

Resource complementarity is decisive in an alliance as such a combination of resources manages to generate effects that are superior to that generated by the resources separately by each partner. In addition, if this combination is inimitable, it will achieve advantages over the other rivals. We may add that a firm with an alliance portfolio can even solely combine resources from various partners or with its own, making it more difficult for others to manage to imitate such a combination.

In different studies, the idea that network resource complementarity guarantees the alliance success has been tested as it increases the company value and the level of firm performance (Chung et al., 2000; De Leeuw et al., 2014; Kale \& Singh, 2009; Wassmer, 2007; Zheng et al., 2013). Other studies have even affirmed that complementarity should be considered before the alliance formation and that it influences performance (Chung et al., 2000; Gulati, 1995; Gulati, 2007; Kim, 2014; Lavie, 2007; Zheng et al., 2013).

If complementarity is important at a dyadic level, it is also important at the level of the alliance portfolio. Thus, different researchers emphasized that when incorporating new alliances, the new complementarities that they will contribute should be carefully examined to see whether they will cause any conflict with the previous members (Caner \& Tyler, 2013; Wassmer, 2007) and whether they will create less value.

Nevertheless, there are companies that prefer redundant resources, particularly in knowledge and information, because they bring a higher level of trust and reliability (Gulati, 2007; Lee, 2007). Dussauge, Garrette and Mitchell (2000) detailed that the partners in a large-scale alliance tend to cooperate with those with similar resources and skills. Ahuja et al. (2009) proposed a nonmonotonic resource similarity effect on alliance formation. Once again, the relation between complementarity and performance is not clearly established in the literature, producing contexts where it is better to obtain partner redundant resources and where the relation might not be linear. Therefore, we propose the following hypothesis:

\section{H3: Alliance resource complementarity will be related to the focal firm} performance.

Moreover, in light of the above, complementarity is usually associated with heterogeneity and diversity because it is believed that a focal firm will seek different resources to those that it already has when it creates an alliance. Thus, the heterogeneous partners are the ones who provide the resources that differ from the focal company resources. Some studies such as those by Baum et al. (2000), Lavie (2007), Burt (1992), Sakakibara (1997), Mitsuhashi and Greve (2009) and Wassmer (2007) indicate this tendency. Complementarity is therefore defined in opposition to partner overlapping and network redundancy and inefficacy (Abuzaid, 2014; Lin, 2012), caused by company homogeneity, which leads us to think that heterogeneity will generate further complementarity. Moreover, alliance portfolio diversity — or egonet diversityimplies multiple sources that will generate benefits from the created synergies (Duysters \& Lokshin, 2011). In other words, heterogeneous partners and alliance portfolio diversity will mean that the firm has different and complementary resources to its own because partner and resource redundancy is either eliminated or severely limited. 
Finally, complementarity may also be said to have a mediatory effect in the relation that both partner heterogeneity and alliance portfolio diversity have with performance. Therefore, we propose the following hypotheses:

H4a: The more the partner's heterogeneity, the more likely they will be able to achieve complementary resources.

H4b: The greater the alliance portfolio diversity, the greater the likelihood of them achieving more complementary resources.

H5a: Resource complementarity in an alliance portfolio mediates the relation between partner heterogeneity and focal firm performance.

H5b: Resource complementarity in an alliance portfolio mediates the relation between alliance portfolio diversity and focal firm performance.

\section{Methods}

\subsection{Sample}

The airline industry was selected for our analysis of how these three aspects (partner heterogeneity, alliance portfolio diversity, and resource complementarity) influence performance. In the airline business, there is a multitude of alliances and other collaborative agreements between firms and large international groups that operate around the world and compete at a global level. Airlines enter into simultaneous alliance agreements with a relatively large number of airline companies such that the portfolio joint management is also a standard practice. In this way, the multiple networks created in this industry may be examined. Although interfirm collaboration has existed in this sector ever since its creation, the process has speeded up over recent years, with the alliance and group emergence operating together. It is a widely used context in the strategic alliance analysis (Casanueva, Gallego \& Sancho, 2013; Gimeno, 2004; Gomes-Cassares, 1994; Lazzarini, 2007; Shah \& Swaminathan, 2008; Wassmer, 2007).

In addition, the airline sector permits a clear identification of the key resources that define competition within it. More specifically, if we consider only market resources, destinations to which the airlines fly and their routes represent one of the most relevant resources in the industry's success (Wassmer, 2007). However, destinations have other added components that involve physical resources such as land-based services, maintenance, and so on. Therefore, airline sector allows the proposed relations to be studied, both because of the clear identification of each alliance that participates in the alliance portfolio and the possibility of sharing with the partners.

In this study, if two airlines entered into a codeshare agreement, an alliance was considered to exist between them (Min \& Mitsuhashi, 2012). A codeshare means an airline can sell seats to its clients on the other company's flights with which it has an agreement. This arrangement means that an airline company can fly to destinations that it does not itself offer because of its alliances with its partners. In a codeshare alliance that is shared, partners can incorporate the destination in its routes, but the resource remains under the control of the firm that holds it. In this industry, destinations are a key resource, whether understood as an element in a network structure or as a market (Wassmer \& Dussauge, 2012).

\subsection{Data}

Data from the largest 200 firms in the industry, reported by Airline Business journal, were used in the study. Within this set of firms, there were some groups, which meant 
that a total of 214 airline companies were actually selected. Finally, those that had no codeshare agreements were filtered out, leaving a total of 135 airline companies with a turnover of $75 \%$ of the total industry income.

The data required to perform the study were compiled on the 135 firms that constitute the 135 portfolios under analysis. In total, over 1700 codeshare agreements were identified among them. The datasets for the identification of the alliances were extracted from the databases of Air Transportation Intelligence, Business-Alliance Survey, and International Civil Aviation Organization (ICAO) corresponding to 2011, facilitated by Flightglobal, and a time series updated to 2012 was used for other sorts of operative, financial, and traffic data.

The relational data that permitted the construction of the alliance portfolio were sourced from the Business-Alliance Survey. This information implies a data set that has been used in conventional works and has been updated every year for over a decade (Gimeno, 2004). As these data sources are many and varied, they were compared with the programmed codeshares in GDS, published in the Airline Route report of August 8, 2011. The congruency of the codeshare alliances in the study was almost complete. The data on the destinations were obtained from the individual records of each airline included in the Flightglobal database. The operational, financial, and traffic data were consulted from those same records but with a 2-year difference, which had been obtained from ICAO and from the annual reports of the airlines. Complete data were available, but the financial information presented here is standardized in dollars as they are published in the local currency (indicating the exchange rate at each point in time). Other historic data on the airlines (employees, destinations, and types of airline) were also individually consulted in those records. In a few cases, where the database presented no up-to-date or reliable data on the number of employees and on the particular destinations of some small partners of the 135 airlines under analysis, those partners were not considered as they represented only a very small part of the 1700 alliances under analysis.

\subsection{Variables}

\subsubsection{Dependent variable}

1) Results: Operating results are an acknowledged reference in the airline sector and were used as an indicator to study performance. Operating results were measured in a similar way to Casanueva et al. (2013). The companies' total turnover throughout 20092012 was used to calculate results expressed in monetary and physical terms (Assaf and Josiassen, 2012). We selected 2012 because that year reflects the alliance performance in earlier years. The used indicators were as follows:

a) Mingpaskm: income per passenger transported over kilometers flown. This ratio is often employed to express demand for each company in the airline industry. It expresses the income generated by passenger traffic.

b) Loadfactor: this variable indicates the passengers per kilometer flown in relation to available seat kilometers. Therefore, it implies a capacity utilization measure in the industry (Lazzarini, 2007).

c) Operating result (MResOper): yielded by the difference between income and operating costs. These come from its own business activity.

\subsubsection{Independent variables}

1) Heterogeneity: Heterogeneity is a measure of the differences between the focal firm's characteristics and each one of their partners' characteristics. It may be measured 
by airline type or segment in which the airline operates, its size, the number of its destinations, and airplane fleet. Four indicators of heterogeneity are therefore presented:

a) Heterogeneity by type of airline (hAirlines): its indicator is the percentage of focal firm partners that belong to subsectors other than that of the focal firm with regard to all of the focal firm partners. The database distinguished five subsectors: low-cost companies, region, charter, major carriers, and airline freight carriers. First, the average number of different companies by type of subsector with which the focal firm has established a codeshare alliance was calculated up until 2011. When there was no subsector coincidence between the focal company and the partner, it was assigned a value of 1 and otherwise 0 . Then, heterogeneity was established with regard to the total number of alliances; in other words, the global estimate of the focal airline company partners divided by the number of partners not from the same subsector as the focal firm.

$H a($ hAirlines $)=\frac{\text { partners }_{\text {subsector }}}{\text { codeshare alliance }}$

The calculation of the indicators is illustrated by taking the example of a fictitious airline (Airfocal) that maintains relations with another four, whose characteristics are given in Table 2. The calculations of the different indicators that will be covered to measure heterogeneity, diversity, and complementarity are given in Table 3 . In Table 3, the indicator hAirlines has a value of 0.25 for Airfocal.

Table 2: Example of the airline Airfocal portfolio

\begin{tabular}{|l|l|l|l|l|l|}
\hline Name & $\begin{array}{l}\text { Airline } \\
\text { type }\end{array}$ & $\begin{array}{l}\text { Number of } \\
\text { employees }\end{array}$ & $\begin{array}{l}\text { Number of } \\
\text { destinations }\end{array}$ & Fleet & $\begin{array}{l}\text { Shared } \\
\text { destinations }\end{array}$ \\
\hline Airfocal & Major & 10000 & 50 & 100 & \\
\hline Airpartner & Major & 20000 & 200 & 300 & 30 \\
\hline Airregional & Low cost & 3000 & 30 & 50 & 25 \\
\hline Airallied & Major & 15000 & 100 & 150 & 20 \\
\hline Aircoop & Major & 10000 & 70 & 150 & 0 \\
\hline
\end{tabular}

Table 3: Example of the calculation for the airline Airfocal indicators

\begin{tabular}{|c|c|}
\hline Variable & Result \\
\hline hAirlines & $\frac{1}{4}=0.25$ \\
\hline hrelSize & $\frac{\frac{\mid 10000-200000}{10000+20000}+\frac{|100000-20000|}{100000+20000}+\frac{\mid 100000-15000}{10000+15000}+\frac{|10000-10000|}{10000+10000}}{4}=0.268$ \\
\hline hrelDestinations & $\frac{\frac{50-200 \mid}{50+200}+\frac{\mid 50-200}{50+90}+\frac{|50-100|}{50+100}+\frac{|50-70|}{50+70}}{4}=0.338$ \\
\hline hrelFleet & $\frac{\frac{|100-300|}{100+300}+\frac{|100-50|}{100+50}+\frac{|100-150|}{100+150}+\frac{|100-150|}{100+150}}{4}=0,08$ \\
\hline divAirline & $1-\left[\left(\frac{3}{4}\right)^{2}+\left(\frac{1}{4}\right)^{2}\right]=0,374$ \\
\hline divSize & $\frac{\sqrt{\frac{(20000-12000)^{2}+(3000-12000)^{2}+(15000-12000)^{2}+(10000-12000)^{2}}{4}}}{\frac{20000+10000+15000+10000}{4}}=0.605$ \\
\hline divDestinations & $\frac{\sqrt{\frac{(200-100)^{2}+(30-100)^{2}+(100-100)^{2}+(70-100)^{2}}{4}}}{\frac{200+30+100+70}{4}}=0.726$ \\
\hline
\end{tabular}




\begin{tabular}{|c|c|}
\hline \multirow[t]{3}{*}{ divFleet } & $(1625-700)^{2}+(162,5-50)^{2}+(1625-150)^{2}+(1625-150)^{2}$ \\
\hline & $\sqrt{4}$ \\
\hline & $900+50+150+150$ \\
\hline CompleAbs & 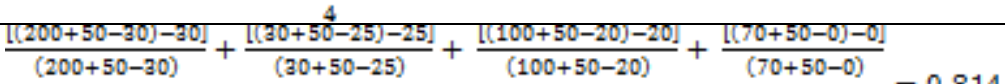 \\
\hline & $4 \quad=0.814$ \\
\hline CompleFocal & $\frac{\frac{(50-20)}{50}+\frac{(50-25)}{50}+\frac{(50-20)}{50}+\frac{(50-0)}{50}}{4}=0.575$ \\
\hline
\end{tabular}

b) Heterogeneity by size (hrelSize): first, we calculated the average number of employees in each company between 2004 and 2011. Then, we found the differences between the average size in the focal firm and each of its partners in the codeshare agreements. We also calculated the sum of the average number of employees in the focal firm and in each of its partners and divided the absolute value of the differences by the totals for each partner. We then totaled all these divisions. Finally, we divided the resulting number by the total number, ' $N$ ', of the codeshare alliances of the focal firm.

$H t($ hrelSize $)=\frac{\frac{|M e i-M e j|}{M e i+M e j}+\frac{|M e i-M e k|}{M e i+M e k}+\ldots+\frac{\mid \text { Mei } i-M e n \mid}{M e i+M e n}}{N}$

where

$\mathrm{Me}_{\mathrm{i}}$ is the average number of employees between 2004 and 2011 in the focal firm,

$\mathrm{Me}_{\mathrm{j}}, \mathrm{k}$ to $\mathrm{n}$ is the average from 2004 to 2011 of the employees in company $\mathrm{j}, \mathrm{k}$, or $\mathrm{n}$, which are focal firm partners in codeshare agreements,

$\mathrm{N}$ is the total number of codeshare alliances into which focal firm has formed.

The result for Airfocal was 0.268 .

c) Heterogeneity by a number of destinations (hrelDestinations): this is similar to the previous one, however, considering the number of destinations in each alliance in 2011. In other words, it is the average total of each ratio that was obtained by calculating the difference between the destinations of two partners divided by the sum of the destinations that link them both.

$H t($ hrelDestinations $)=\frac{\frac{|D i-D j|}{D i+D j}+\frac{|D i-D k|}{D i+D k}+\ldots+\frac{|D i-D n|}{D i+D n}}{N}$

where

$\mathrm{D}_{\mathrm{i}}$ is the number of focal firm destinations in 2011,

$\mathrm{D}_{\mathrm{j}, \mathrm{k}}$ to $\mathrm{n}$ is the number of companies $\mathrm{j}, \mathrm{k}$, and $\mathrm{n}$ destinations in 2011 , which are focal firm partners in codeshare agreements, and $\mathrm{N}$ is the total number of focal firm codeshare alliances.

This indicator yielded a value of 0.338 , as given in Table 3 .

d) Heterogeneity by fleet (hrelFleet): this is calculated in a similar way to that of previous ones but considering each company's fleet in 2011. In the same way as in the preceding cases, it is the measure of the ratios obtained by calculating the absolute difference between the fleets of each alliance of the focal firm and the sum of the fleets of each dyad.

$H f($ hrelFleet $)=\frac{\frac{|F i-F j|}{F i+F j}+\frac{|F i-F k|}{F i+F k}+\ldots+\frac{|F i-F n|}{F i+F n}}{N}$

where

$F_{i}$ is the number of planes owned by focal firm $i$ in 2011

$F_{j}, k$ to $n$ is the number of planes owned by the partners $j, k$, and $n$, which are focal firm (i) codeshare partners.

$\mathrm{N}$ is the total number of focal firm codeshare alliances. 
The value yielded for Airfocal was 0.308 .

2) Diversity: the degree to which the focal firm partners (its egonet members) differ between each other - without including the focal firm - should be confirmed before studying their diversity. The indicators were based on measures of diversity between the alliance portfolio member characteristics. Four indicators of diversity were constructed between the portfolio airlines:

a) Diversity by type of airline (divAirlines): using the coefficient of diversity suggested by Blau (Blau, 1977; Gulati, 1999):

divAirline $=1-\sum \mathrm{p}_{\mathrm{ia}}{ }^{2}$,

where

$\mathrm{p}_{\mathrm{ia}}$ is the proportion existing in the alliance portfolio of each type of airline according to the subsector to which it belongs. Thus, the diversity existing between the group was measured as this coefficient expresses the extent to which the portfolio members differ between each other, where 1 is the maximum diversity in the group and 0 the minimum (or the maximum similarity).

b) Diversity by size (divSize): we used the coefficient of variation, i.e., a measure of relative distribution, in particular, the standard and average deviation. In other words,

$$
D t(\operatorname{divSize})=\frac{\sigma t}{\bar{x} t}
$$

where

$\overline{\mathrm{x}} \mathrm{t}$ is the arithmetic mean of the number of employees of all the partners of the focal firm, without counting the focal firm itself. The average number of employees in each partner between 2004 and 2011 was calculated to establish the number of their employees.

$\sigma \mathrm{t}$ is the standard deviation with regard to the earlier measure.

In this way, if the standard deviation were 0 , it would be because all the partners had the same number of employees, in which case there would be minimum diversity: the higher the value of $\sigma$ in relation to 0 , the greater the diversity.

c) Diversity by a number of destinations (divDestinations): this is similar to the previous ones but considering the destinations of the portfolio members as of 2011. In other words, we used the coefficient of variation, for which purpose we calculated the average number of destinations held by the alliance portfolio partners (excluding the focal firm) and the standard deviation between them.

$$
D d \text { (divDestinations) }=\frac{\sigma d}{\bar{x} d}
$$

$\bar{x} \mathrm{~d}$ is the arithmetic mean of the number of destinations in 2011 of all the partners of the focal firm, without counting the focal firm.

$\sigma \mathrm{d}$ is the standard deviation with regard to the earlier measure.

d) Diversity by fleet (divFleet): this is similar to the previous ones but on this occasion, considering the portfolio members fleet in 2011 (excluding focal firm). In other words, we calculated the coefficient of variation (standard deviation divided by the average) of the fleet owning by all the alliance portfolio partners without considering focal firm.

$$
D f(\text { divFleet })=\frac{\sigma f}{\bar{x} f}
$$

where

$\overline{\mathrm{x}} \mathrm{d}$ is the arithmetic average of the fleets owning by all the alliance portfolio members without counting focal firm.

$\sigma \mathrm{d}$ is the standard deviation of the earlier measure. 
The value of the four preceding indicators of diversity for Airfocal was 0.374, 0.605, 0726, and 0.634 as given in Table 3.

3) Complementarity: this variable measures access through the alliance to partner resources not owned by focal firm. The resources are complementary when they are not redundant, in other words, when the other company does not possess them.

Nonredundant resources permit greater synergy. The selected resource is the set of partner destinations that each company can access, which may be seen as the markets that each airline penetrates (Wassmer \& Dussauge, 2012). Complementarity is defined as access to destinations to which the focal company had not transported passengers before. Therefore, two airlines will be absolutely complementary when they share no destination. In addition to eliminating redundancy in the destination network, this complementarity enlarges the places to which each company can travel, completing its route network, which generates synergic effects for the airline. Set theory was employed to measure this variable:

a) Complementarity: the variable measures the percentage of different destinations between each other that the focal firm has with each of its partners with regard to the total number of destinations that they all have between each other. It is calculated as a measure of all coefficients of the rest of the union and the intersection of the sets of two airlines destinations divided between the union of both sets (Mitsuhashi \& Greve, 2009). Expressed as:

$$
C A(\text { CompleAbs })=\frac{\sum|A \cup B j-A \cap B j| /|A \cup B j|}{N}
$$

where

A is the set of destinations of the focal firm

$\mathrm{Bj}$ is the set of destinations of each of the partners $\mathrm{j}$ in code-share alliances.

$A U B_{j}$ represents the sum of the set of destinations of the focal firm and its partner (shared and separate)

$A \cap B_{j}$ represents the set of common destinations between the focal firm and its partner

$\mathrm{N}$ is the number of partners in code-share alliances with the focal firm.

This indicator yielded a value of 0.814 for Airfocal.

b) Focal complementarity: complementarity can also be analyzed from the partner's point of view; if focal firm has resources that are complementary to its own, the partner will be more willing to ally itself and/or to share its resources with focal firm.

Therefore, the extent to which a firm is complementary for its partners was also measured, which was done with the coefficient of the set of focal firm destinations minus the intersection of the sets under consideration, divided by the first airline destinations:

$$
C F(\text { CompleFocal })=\frac{\sum A-|A \cap B j| / A}{N}
$$

The value of this indicator for Airfocal would be 0.575 (Table 3).

\subsubsection{Control variables:}

1) Age: this variable represents the firm ages that constitute the sample. The reference year for age was taken as 2011.

2) Fleet: it represents the firm size in terms of the number of its planes that are operative in 2011.

3) Size: it represents each airline alliance portfolio size; in other words, the number of partners with which they maintain codeshare agreements. 


\section{Results}

The partial least squares (PLS) method was used to analyze the data because of the model complexity (several constructs and indicators) and its causal predictive character (Chin \& Newsted, 1999). As indicated earlier, our sample contains 135 airlines.

Reinartz, Haenlein and Henseler (2009) pointed out that PLS is suitable for our size sample $(<250)$. Moreover, PLS is considered the most appropriate method to treat datasets of secondary data, which in our case were extracted from the database (Gefen, Rigdon, \& Straub, 2011).

Figure 2: PLS model.

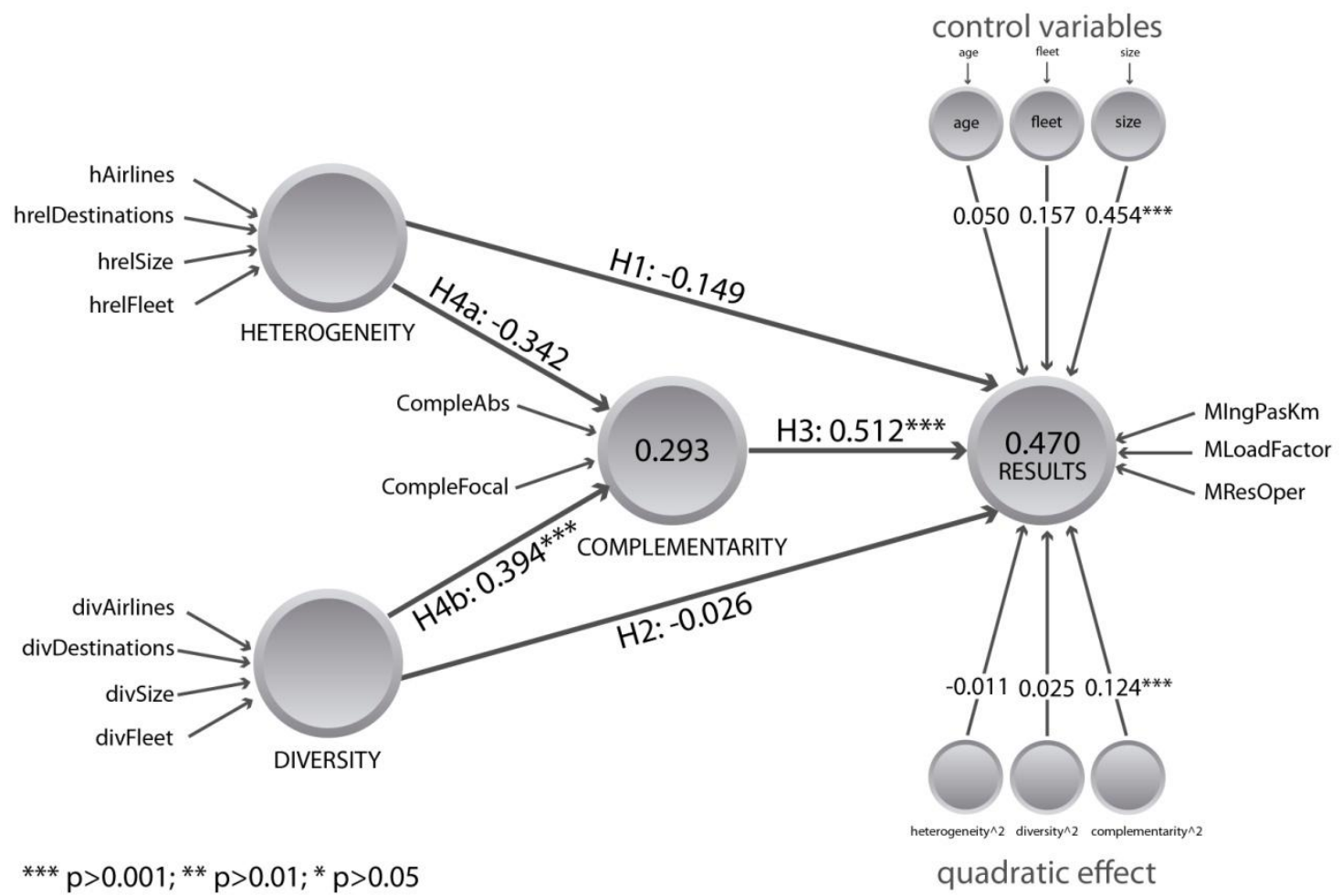

Figure 2 represents the structural model. The relations between the basic variables that allow us to test our hypotheses (heterogeneity, diversity, and complementarity and the results) with their indicators, but also three control variables and another three allow us to analyze the quadratic effects. In hypotheses 1,2 , and 3, neither the type of relation between heterogeneity, diversity, and complementarity is specified in the results nor is its sign and the nonlinear effect of these relations are analyzed in the model. The twostage approach was used to analyze the quadratic effects (Henseler, Fassott, Dijkstra \& Wilson, 2012).

In a structural equation model, all constructs (latent variables) were associated with a set of indicators that can have either a reflective or a formative association with those constructs. A reflective relation implies that the indicators are a representation of the construct. A formative relation implies that the indicators produce or contribute to the construct (Fornell, 1982). In the aforementioned case, the measures or indicators represent characteristics that collectively explain the content of the construct. Following the recommendations given by Jarvis, MacKenzie and Podsakoff (2003), the model indicators and variables were evaluated, and in the light of certain criteria, they were considered formative. There are studies that have used this same option for similar 
variables to those of the proposed model (Crosby, Evans \& Cowles, 1990; Jarvis et al., 2003).

In the evaluation of the measurement model, the formative variables do not need to be correlated, and it is assumed that they are error free, so the traditional evaluation of reliability and validity is not considered applicable (Bagozzi, 1994). In contrast with the analysis of the models based on reflective indicators, those based on formative indicators are less formalized, and different strategies should be considered (Diamantopoulos \& Siguaw, 2006; Petter, Straub \& Rai, 2007). The possible problems of multicollinearity should be considered to estimate reliability. The variance inflation factor (VIF) (Diamantopoulos \& Siguaw, 2006) was used, which should be below 3.3. In Table 4, we can see that all the indicators are below that level.

Table 4: Measurement model and indicator weights VIF values

\begin{tabular}{|l|l|l|l|l|}
\hline & VIF & Weights & t Statistics & P Values \\
\hline CompleAbs & 2.521 & -0.965 & $\mathbf{4 . 1 3 2}$ & $\mathbf{0 . 0 0 0}$ \\
\hline CompleFocal & 2.521 & 1.544 & $\mathbf{7 . 1 1 0}$ & $\mathbf{0 . 0 0 0}$ \\
\hline MIngPasKm & 1.460 & 1.143 & $\mathbf{1 6 . 2 5 3}$ & $\mathbf{0 . 0 0 0}$ \\
\hline MLoadFactor & 1.219 & -0.144 & 1.122 & 0.262 \\
\hline MResOper & 1.239 & -0.281 & $\mathbf{2 . 5 2 5}$ & $\mathbf{0 . 0 1 2}$ \\
\hline divAirlines & 1.217 & 0.424 & $\mathbf{2 . 1 5 7}$ & $\mathbf{0 . 0 3 1}$ \\
\hline divDestinations & 2.720 & 0.431 & 1.466 & 0.143 \\
\hline divFleet & 1.608 & 0.298 & 1.540 & 0.124 \\
\hline divSize & 3.129 & 0.142 & 0.511 & 0.609 \\
\hline hAirlines & 1.307 & -0.618 & 1.134 & 0.257 \\
\hline hrelDestinations & 1.412 & 0.383 & 0.937 & 0.349 \\
\hline hrelFleet & 1.201 & 0.207 & 0.648 & 0.517 \\
\hline hrelSize & 1.461 & 0.785 & 1.499 & 0.134 \\
\hline
\end{tabular}

The next step was to analyze the validity of the construct (Petter et al., 2007). The analysis of the indicator weights and their meaning is given in Table 4 . We can see that there are various indicators with insignificant weights. Following the criteria given by Hair et al (2014), all those indicators with loadings above 0.5 should be retained in the model. If we analyze the factor loading with insignificant weights (Table 5), the only indicators that we would have to eliminate would be MLoadFactor and hAirlines.

Nevertheless, given the information that they contain, we decided to retain them in the study to avoid altering the conceptual domain of the formative construct (Jarvis et al., 2003; Roberts \& Thatcher, 2009).

Table 5: Loading indicator

\begin{tabular}{|l|l|}
\hline & Loads \\
\hline MLoadFactor -> RESULTS & 0.214 \\
\hline divDestinations -> DIVERSITY & 0.867 \\
\hline divFleet -> DIVERSITY & 0.689 \\
\hline divSize -> DIVERSITY & 0.816 \\
\hline hAirlines -> HETEROGENEITY & -0.137 \\
\hline
\end{tabular}




\begin{tabular}{|l|l|}
\hline hrelDestinations -> HETEROGENEITY & 0.610 \\
\hline hrelFleet -> HETEROGENEITY & 0.528 \\
\hline hrelSize -> HETEROGENEITY & 0.729 \\
\hline
\end{tabular}

Having analyzed the measurement model, we moved on to the structural model. First, we analyzed construct multicollinearity. In Table 6, we see VIF statistic for the constructs. In this case, VIF value should be below 5 (Hair et al., 2014). All constructs complied with this criterion.

Table 6: Structural model VIF values

\begin{tabular}{|l|l|l|}
\hline & COMPLEMENTARITY & RESULTS \\
\hline COMPLEMENTARITY & & 2.207 \\
\hline complementarity2 & & 2.186 \\
\hline DIVERSITY & 1.006 & 1.566 \\
\hline diversity $^{2}$ & & 1.288 \\
\hline HETEROGENEITY & 1.006 & 1.250 \\
\hline heterogeneity & & 1.401 \\
\hline RESULTS & & \\
\hline age & & 1.131 \\
\hline fleet & & 1.138 \\
\hline size & & 1.540 \\
\hline
\end{tabular}

Finally, we evaluated the path coefficients that showed the relations between the variables. To do so, bootstrapping was applied to 5000 samples (Hair et al., 2014). The results are given in Table 7. The explained variance $\left(R^{2}\right)$ reached a level of 0.293 for complementarity and 0.470 for the results. Those values are above the minimum of 0.1 , as indicated by some authors (Chin, 1998; Falk \& Miller, 1992), and even 0.25 that Hair et al (2014) recommended.

With regard to the control variables, the only one that showed a significant and positive relation with the results $(\beta=0.454$ and $p=0.000)$ was size. This result means that airlines improve their results in relation to their portfolio size, in other words, when the number of partners increases.

If we analyze the linear relations, neither heterogeneity (H1) nor diversity (H2) has a significant relation with the results. Moreover, heterogeneity is not associated with complementarity in a significant way (H4a). We do see a significant and positive relation ( $\beta=0.394$ and $p=0.000)$ between diversity and complementarity $(\mathrm{H} 4 \mathrm{~b})$, indicating that the greater the differences between the partners that constitute the alliance portfolio, the higher the probability of obtaining complementary resources. Finally, complementarity is the only variable that shows a significant linear relation with the results $(\beta=0.512$ and $p=0.000)$, indicating that the more complementary the alliance portfolio resources, the better the firm performance $(\mathrm{H} 3)$.

Table 7: Path coefficients

\begin{tabular}{|l|l|l|l|}
\hline & $\begin{array}{l}\text { Path } \\
\text { coeff. }\end{array}$ & t statistics & P Values \\
\hline COMPLEMENTARITY $->$ & 0.512 & 5.003 & $\mathbf{0 . 0 0 0}$ \\
\hline
\end{tabular}




\begin{tabular}{|c|c|c|c|}
\hline RESULTS & & & \\
\hline complemantarity $^{2}$-> RESULTS & 0.124 & 2.150 & 0.032 \\
\hline $\begin{array}{l}\text { DIVERSITY -> } \\
\text { COMPLEMENTARITY }\end{array}$ & 0.394 & 3.849 & 0.000 \\
\hline DIVERSITY -> RESULTS & -0.026 & 0.270 & 0.787 \\
\hline diversity $^{2}$-> RESULTS & 0.025 & 0.347 & 0.728 \\
\hline $\begin{array}{l}\text { HETEROGENEITY -> } \\
\text { COMPLEMENTARITY }\end{array}$ & -0.342 & 1.174 & 0.240 \\
\hline $\begin{array}{l}\text { HETEROGENEITY -> } \\
\text { RESULTS }\end{array}$ & 0.149 & 0.872 & 0.384 \\
\hline heterogeneity $^{2}$-> RESULTS & -0.011 & 0.223 & 0.823 \\
\hline age $->$ RESULTS & 0.157 & 1.494 & 0.135 \\
\hline fleet $->$ RESULTS & -0.050 & 0.615 & 0.538 \\
\hline size -> RESULTS & 0.454 & 4.949 & 0.000 \\
\hline
\end{tabular}

If we analyze the nonlinear relations, we see that complementarity is the only one that continues its significant relation with the results $(\beta=0.124$ and $p=0.032)$. As the sign is positive, we have a $U$-shaped relation. This result shows that complementarity between the focal firm resources and its partners' resources generates better results for that firm if that complementarity is quite small or quite large, whereas intermediate levels of complementarity affect the results to a lesser degree.

Moreover, a more detailed analysis of the relations in the model allows us to analyze the mediating role of complementarity in the relations between partner heterogeneity and alliance portfolio diversity with regard to the firm performance. To do so, we used the analysis suggested by Castro \& Roldán (2013) and Real, Roldán \& Leal (2014). In this way, the values are examined to see whether those obtained in the bootstrapping process of 5000 subsamples of the indirect relations (yielded by multiplying the values obtained in the relation heterogeneity results by complementarity results and diversity results by complementarity results) taking 0 as a value, at a confidence level of $95 \%$, for which purpose percentiles of 2.5 and 97.5 were applied (Chin, 2010; Hayes, 2009; Williams \& MacKinnon, 2008). In the case where some of these intervals contain a negative number, it means that it is inclusive of the value 0 , so the relation of intermediation is not significant. The data show that this condition is only met in the relation in which alliance portfolio diversity and results are mediated by network resource complementarity, having an estimated value of 0.202 , whereas the percentile 2.5 assumed a value of 0.089 and the percentile 97.5 assumed a value of 0.265 . We managed to demonstrate hypothesis $5 \mathrm{~b}$, although $5 \mathrm{a}$ did not have sufficient support.

Finally, indicator $f^{2}$ for the constructs that were significant obtained the following values: 0.224 for complementarity results, 0.060 for complementarity ${ }^{2}$ results, 0.218 for diversity complementarity, and 0.252 for size results. In line with Cohen (1988), values of between 0.15 and 0.35 indicate a moderate size effect. Therefore, only the quadratic relation of alliance portfolio diversity with network resource complementarity has a small effect. This result shows a greater explanatory power of the linear relations rather than the nonlinear relations included in the model.

\section{Conclusions and discussion}

The analysis of the 135 global airlines alliance portfolios configured on the basis of their codeshare alliances has provided an insight into the consequences of the three divergence sources for these alliance portfolios. Moreover, divergence sources are linked to network resources and firm performance. In particular, the analysis has charted 
the way in which partner heterogeneity, alliance portfolio diversity between, and key network resource complementarity in codeshare alliances (destinations) affects the airline operating results. These results have shown support for some, but not all, of the relations presented in the hypotheses.

First, it has been confirmed that the network resource complementarity between partners influences better performance achievement at an operational level (H3). The influence of complementarity in the results is greater if network resource complementarity is quite low or quite high, as shown in the analysis of the quadratic effects. These results contribute new evidence to the debate about whether a better performance is linked to obtaining partner redundant resources that are supplementary to those the focal firm already has or, on the contrary, whether it is linked to obtaining complementary resources that produce synergies. The results suggest that some portfolios function well when similar resources are accumulated to those that the focal firm already owns. This is consistent with the previous arguments that partners that give the firm a higher level of confidence and reliability are sought (Gulati, 2007; Lee, 2007). Another factor that can explain the curvilinear form of the relation is that the firms can use link alliances (in which the complementary resources will be important; this kind of alliance fits in our dyadic alliance between heterogeneous partners or our diverse alliance portfolio) or scale alliances (in which the firms tend to ally themselves with firms that have similar resources; this type of alliance corresponds with our dyadic alliance between homogeneous partners or our similar alliance portfolio) (Dussauge et al., 2000). According to a previous argument, Garrette, Dussage, Castañer and Mulotte (2007) suggest that domain-specific know-how generates better performance in scale alliances. Therefore, our results suggest that firms should be specialized in one type of alliance. That can be explained because companies reach their own best performance when they are specialized in homogeneous (similar) partners - sharing redundant or supplementary resource - or heterogeneous (diverse) ones - sharing complementary resources. In other words, our results indicate that the best option is to have an alliance portfolio profile specialized either in link alliances or in scale alliances. The decision will depend on the alliance's previous experience.

However, it may also be because market resources have been used and, due to these sorts of resource characteristics, that it is positive to gain both supplementary and complementary resources. Therefore, airlines will be interested in gaining their partner's new destinations not only to complete their operational network but also to access the destinations, through partner resources, that these airlines already have but which increase the flight frequency and the possibilities of onward connections. Moreover, the results also showed that at very high percentages of complementarity, the results also improve, referring directly to the synergy and the arguments advanced in a large part of the previous literature (Chung et al., 2000; De Leeuw et al., 2014; Kale \& Singh, 2009; Wassmer, 2007; Zheng et al., 2013).

With regard to heterogeneity, it was possible to neither demonstrate that the best operative results are produced when the partners differ greatly from the focal firm nor demonstrate that greater partner heterogeneity will achieve, as a result, more complementary network resources. Both these relations have been emphasized in a large part of the previous literature. Furthermore, in line with many studies in the literature, which associate the alliance portfolio diversity with greater network resource complementarity and state that this diversity leads to a better performance, the data on the alliance portfolio obtained from the codeshare alliances showed no direct relation between alliance portfolio diversity and performance; however, the effects of mediation do appear, which point to the indirect influence of diversity on performance through 
access to complementary network resources ( $\mathrm{H} 4 \mathrm{~b}$ and $\mathrm{H} 5 \mathrm{~b})$. These results highlight the central role of obtaining partner resource complementarity as a pivotal element in the alliance portfolio construction.

The main contributions of this work are two-fold. First, the differences between a focal firm and its partners in characteristics - partner heterogeneity—affect company performance in a positive way nor the key network resource that are complementary to the focal firm resource, whereas the diversity or variety between partners within a portfolio - alliance portfolio diversity - positively influence both performance (in an indirect manner) and the complementarity network resource achievement. This idea suggests that the effect of divergences or differences is more powerful and positive at the egonet level than at the dyadic relation level with the focal firm. Therefore, the arguments linked to the egonet structure should prevail in the analysis of the alliance configuration (Burt, 1992; Gulati, 1995). Second, the more complementary the alliance resources, the better the firm performance. It appears that the network resource complementarity has an important weightage in the relation. In other words, a relevant factor for the performance improvement in the alliance portfolio configuration is to achieve access to network resources that are complementary to the firm resource endowment and that may be achieved with a more diverse and varied alliance portfolio. This observation implies situating the network resources at the center of the analysis of the portfolio configuration, proposing that the factors linked to the partner characteristics and to their own resources can have a more important effect on performance compared to others that were analyzed more widely by Network Theory, such as network structure and the partner relationship intensity (Gulati, 2007; Lavie, 2008). Previous studies that used the same definition of network resources (Lavie, 2008) have shown that their access improved the company's performance (Casanueva et al., 2013; Lavie, 2007), but they did not include any analysis of whether those network resources were complementary to the focal firm's resources.

In line with the studies by Kim (2014), Wassmer (2007) or Zheng et al. (2013), these results support the idea that complementarity influences the economic performance achievement in a positive way. In addition, it has an indirect influence on the relation between diversity and results because it is important to possess different and complementary results, as Lin (2012) and Sakakibara (1997) have argued.

Therefore, as maintained by the proposed hypotheses, the data have shown that having a very diverse alliance portfolio in no way implies excessive expenditure on tasks related to coordination to overcome all difficulties (De Leeuw et al., 2014; Duysters \& Lokshin, 2011; Faems et al., 2010; Lahiri \& Narayanan, 2013; Park et al., 2014).

This work has shown that the physical and market resource complementarity in alliances may, in an acceptable way, combine associations with highly divergent partners. These results set out the need to research other industries, with physical resources and resources related to knowledge and innovation. Unlike earlier studies, alliance portfolio diversity and partner heterogeneity within the same industry have been studied by analyzing subsector membership or segments rather than interindustry differences.

At a theoretical level, our research has contributed to the better knowledge of various important issues raised in the strategic literature. First, a conceptual clarification has been made of the three principal sources of portfolio divergence that are linked to network resources. This will mean that we may advance with the proposed research agenda in a more orderly manner (Gulati et al., 2011; Wassmer, 2010). Second, the implications of the study have pointed toward situating alliance management within a 
suitable analysis of the network resources that are sought and shared within the alliance (Gulati, 2007; Lavie, 2008). An acceptable analysis of network resources with regard to typology, endowment, accumulation, access, and mobilization by partners will permit the maximum exploitation of both synergies and complementarity, thereby improving firm performance and achieving competitive advantages (Gulati et al., 2011). Third, as this work has highlighted, the consideration of physical and market resources can be very relevant when studying firm behavior in terms of their interorganizational ties, as opposed to a large part of the literature that has focused (and it has generated theory) on intangible resources.

Our study also has implications for practice. Accordingly, on the one hand, firms should form alliances with other companies unlike themselves to obtain better performance, and on the other hand, they should search for partners endowed with complementary resources to improve their performance. This recommendation sets out the need for global alliance portfolio management to have a place in the firm, whether through line managers or specific department work, similar to that in some firms and particularly in the industry under study (De Man, Roijakkers, \& De Graauw, 2010; Dyer et al., 2001; Faems et al., 2010; Kale et al., 2002).

The study also presents a series of limitations. First, only one resource has been analyzed to study complementarity. Despite it being a very relevant industry resource (Wassmer \& Dussauge, 2012), which is the principal motive for forming the type of alliances under consideration, i.e., codeshare, the information that relates to the variable network resource complementarity has, it appears, been excessively influenced by this relevance. Second, the indicators used to measure the three concepts (partner heterogeneity, alliance portfolio diversity, and network resource complementarity) that have been analyzed were the researcher's choice. Other firm characteristics and other types of measures to confirm differences and similarities may be considered. Equally, a further limitation of our research is that we gave no consideration to other alliances except codeshares so that each airline alliance portfolio under study is really complete. Another limitation is that most of the heterogeneity and diversity indicators are related to firm size (number of employees, number of destinations, and fleet size), and they are correlated. Finally, the chosen industry is complex as it brings together very different firms and their particular circumstances about competence and globalization, which may perhaps be reflected in the results.

Future lines of research will mainly seek to tackle these limitations. For example, our study could be repeated in another industry - other than airlines - and in a particular airline company segment to test the results. A second research line would be the consideration of other types of intangible resources, as new arguments may arise to establish differences in the relations, thus paying attention to the type of resources under consideration and confirm how the results obtained from the context under analysis fit in with the previous literature. Moreover, other indicators could also be used for the variables that were employed. In addition to seeking alternative means of measurement, it would be interesting to find a way of measuring the partner's willingness to join the alliance portfolio. Another limitation was that we worked by taking secondary data into account. An interesting research line would be the inclusion of other types of alliances, whether horizontal, such as frequent flyer programs, or vertical, and alliances with firms from other sectors. This approach would permit new divergence sources to be included in the alliance portfolio as done in previous research (Duysters \& Lokshin, 2011; Lavie $\&$ Miller, 2008) or include the interesting question of multiplexity in the alliance portfolio (Cui \& O'Connor, 2012; Sarkar et al., 2009). Finally, it would be interesting to include other ways of considering the differences proposed by network approach, such 
as structural heterogeneity (Ahuja et al., 2009), cultural distances (Lavie \& Miller, 2008), and multiplexity in strategic alliances (Cui \& O'Connor, 2012).

\section{Acknowledgment}

This research was supported by the Ministerio de Economía y Competitividad (ECO2013-45329-R) and the Ministerio de Educación, Cultura y Deporte (Programa de Ayudas de Formación del Profesorado Universitario), Spain.

\section{References}

Abuzaid, A.N.A. (2014). The Impact of Strategic Alliance Partner Characteristics on Firms' Innovation: Evidence from Jordan. International Journal of Business and Management, 9(3), 77-87.

Ahuja, G. (2000). The duality of collaboration: Inducements and opportunities in the formation of interfirm linkages. Strategic Management Journal, 21(3), 317-343.

Ahuja, G., Polidoro, F., \& Mitchell, W. (2009). Structural homophily or social asymmetry? The formation of alliances by poorly embedded firms. Strategic Management Journal, 30(9), 941-958.

Assaf, A.G., \& Josiassen, A. (2012). European vs. U.S. airlines: Performance comparison in a dynamic market. Tourism Management, 33(2), 17-326.

Bagozzi, R.P. (1994). Structural equation models in marketing research: Basic principles. In R.P. Bagozzi, (Ed.), Principles of marketing research (pp. 317-385). Oxford, UK: Blackwell.

Baum, J.A.C., Calabrese, T., \& Silverman, B.S. (2000). Don't go it alone: Alliance network composition and startups' performance in Canadian biotechnology. Strategic Management Journal, 21(3), 267-294.

Beckman, C.M., \& Haunschild, P.R. (2002). Network Learning: The Effects of Partners' Heterogeneity of Experience on Corporate Acquisitions. Administrative Science Quarterly, 47(1), 92-124.

Bettis, R.A., Bradley, S.P., \& Hamel, G. (1992). Outsourcing and industrial decline. The Executive, 6(1), 7-22.

Blau, P.M. (1977). Inequality and heterogeneity. New York, NY: Free Press.

Burt, R.S. (1992). Structural holes: The social structure of competition. Cambridge, MA: Harvard University Press.

Caner, T., \& Tyler, B.B. (2013). Alliance portfolio R\&D intensity and new product introduction. American Journal of Business, 28(1), 38-63.

Casanueva, C., Gallego, A., \& Sancho, M. (2013). Network resources and social capital in airline alliance portfolios. Tourism Management, 36, 441-453. 
Castro, I., Casanueva, C., \& Galán, J.L. (2014). Dynamic evolution of alliance portfolios. European Management Journal, 32(3), 423-433.

Castro, I., \& Roldán, J. L. (2013). A mediation model between dimensions of social capital. International Business Review, 22(6), 1034-1050.

Chin, W.W. (1998). The partial least squares approach to structural equation modeling. In Marcoulides, G.A. (Ed.), Modern Methods for Business Research (pp. 295336). Mahwah, NJ: Lawrence Erlbaum.

Chin, W.W. (2010). How to write up and report PLS analyses. In V.E. Vinzi, W.W. Chin, J. Henseler and H. Wang (Eds.), Handbook of Partial Least Squares: Concepts, Methods and Applications (pp. 655-690). Berlin: Springer.

Chin, W.W., \& Newsted, P.R. (1999). Structural equation modelling analysis with small samples using partial least squares. In R. Hoyle, (Ed.), Statistical strategies for small sample research (pp. 307-341). Thousand Oaks, CA: Sage.

Chung, S., Singh, H., \& Lee, K. (2000). Complementarity, status similarity and social capital as drivers of alliance formation. Strategic Management Journal, 21(1), 122.

Cohen, J. (1988). Statistical power analysis for the behavioral sciences (2nd ed.). Hillsdale, NJ: Erlbaum

Collins, J., \& Riley, J. (2013). Alliance Portfolio Diversity and Firm Performance: Examining Moderators. Journal of Business and Management, 19(2), 35-50.

Crosby, L.A., Evans, K.R., \& Cowles, D. (1990). Relationship Quality in Services Selling: An Interpersonal Influence Perspective. Journal of Marketing, 54(July), 68-81.

Cui, A.S., \& O'Connor, G. (2012). Alliance Portfolio Resource Diversity and Firm Innovation. Journal of Marketing, 76(4), 24-43.

De Leeuw, T., Lokshin, B., \& Duysters, G. (2014). Returns to alliance portfolio diversity: The relative effects of partner diversity on firm's innovative performance and productivity. Journal of Business Research, 67(9), 1839-1849.

De Man, A.-P., Roijakkers, N., \& De Graauw, H. (2010). Managing dynamics through robust alliance governance structures: The case of KLM and Northwest airlines. European Management Journal, 28(3), 171-181.

Dess, G.G., Rasheed, A.M., McLaughlin, K.J., \& Priem, R.L. (1995). The new corporate architecture. The Academy of Management Executive, 9(3), 7-18.

Diamantopoulos, A., \& Siguaw, J.A. (2006). Formative versus reflective indicators in organizational measure development: A comparison and empirical illustration. British Journal of Management, 17(4), 263-282. 
Dussauge, P., Garrette, B., \& Mitchell, W. (2000). Learning from competing partners: Outcomes and durations of scale and link alliances in Europe, North America and Asia. Strategic Management Journal, 21(2), 99.

Duysters, G., De Man, A.P., \& Wildeman, L. (1999). A network approach to alliance management. European Management Journal, 17(2), 182-187.

Duysters, G., Heimeriks, K.H., Lokshin, B., Meijer, E., \& Sabidussi, A. (2012). Do Firms Learn to Manage Alliance Portfolio Diversity? The Diversity-Performance Relationship and the Moderating Effects of Experience and Capability. European Management Review, 9(3), 139-152.

Duysters, G., \& Lokshin, B. (2011). Determinants of Alliance Portfolio Complexity and Its Effect on Innovative Performance of Companies. The Journal of Product Innovation Management, 28(4), 570-585.

Dyer, J.H. (1996). Specialized supplier networks as a source of competitive advantage: Evidence from the auto industry. Strategic Management Journal,17(4), 271-291.

Dyer, J.H., Kale, P., \& Singh, H. (2001). How to Make Strategic Alliances Work. MIT Sloan Management Review, 42(4), 37-43.

Dyer, J.H., \& Singh, H. (1998). The relational view: Cooperative strategy and sources of interorganizational competitive advantage. Academy of Management. The Academy of Management Review, 23(4), 660-679.

Eisenhardt, K.M., \& Schoonhoven, C.B. (1996). Resource-based view of strategic alliance formation: Strategic and social effects in entrepreneurial firms. Organization Science, 7(2), 136-150.

Faems, D., De Visser, M., Andries, P., \& Van Looy, B. (2010). Technology Alliance Portfolios and Financial Performance: Value-Enhancing and Cost-Increasing Effects of Open Innovation. The Journal of Product Innovation Management, 27(6), 785-796.

Falk, R.F., \& Miller, N.B. (1992). A primer for soft modeling. Akron, OH: The University of Akron.

Fornell, C. (1982). A second generation of multi-variate analysis: an overview. In C. Fornell, (Ed.), A second generation of multivariate analysis (pp. 1-21). New York, NY: Praeger.

Garrette, B., Dussauge, P., Castañer, X., \& Mulotte, L. (2007). Do scale alliances with competitors improve product performance? A study of the aircraft industry, 19492000. Retrieved from http://www.hec.fr/Faculte-Recherche/Publications/Cahiersde-recherche/(id)/2720

Gefen, D., Rigdon, E.E., \& Straub, D. (2011). An Update and Extension to SEM Guidelines for Administrative and Social Science Research. MIS Quarterly, 35(2), iii-A7. 
Gimeno, J. (2004). Competition within and between Networks: The Contingent Effect of Competitive Embeddedness on Alliance Formation. Academy of Management Journal, 47(6), 820-842.

Goerzen, A., \& Beamish, P.W. (2005). The effect of alliance network diversity on multinational enterprise performance. Strategic Management Journal, 26(4), 333354.

Golonka, M. (2015). Proactive cooperation with strangers: Enhancing complexity of the ICT firms' alliance portfolio and their innovativeness. European Management Journal, 33(3), 168-178.

Gomes-Casseres, B. (1994). Group versus group: How alliance networks compete. Harvard Business Review, 72(4), 62-67.

Grant, R.M., \& Baden-Fuller, C. (2004). A Knowledge Accessing Theory of Strategic Alliances. Journal of Management Studies, 41(1), 61-84.

Gulati, R. (1995). Social structure and alliance formation patterns: A longitudinal analysis. Administrative Science Quarterly, 40(4), 619-652.

Gulati, R. (1999). Network location and learning: The influence of network resources and firm capabilities on alliance formation. Strategic Management Journal, 20(5), 397-420.

Gulati, R. (2007). Managing network resources, Oxford: Oxford University Press.

Gulati, R., Lavie, D., \& Madhavan, R. (2011). How do networks matter? The performance effects of interorganizational networks. Research in Organizational Behavior, 31, 207-224.

Gulati, R., Nohria, N., \& Zaheer, A. (2000). Strategic networks. Strategic Management Journal, 21(3), 203-215.

Hair, J.F.Jr, Sarstedt, M., Hopkins, L., Kuppelwieser, V.G. (2014). Partial least squares structural equation modeling (PLS-SEM): An emerging tool in business research, European Business Review, 26(2), 106 - 121.

Hamel, G., Doz, Y., \& Prahalad, C.K. (1989). Collaborate with your partners-and win. Harvard Business Review, 67(1), 133-139.

Hayes, A.F. (2009). Beyond Baron and Kenny: statistical mediation analysis in the new millennium, Communication Monographs, 76(4), 408-420.

Henseler, J., Fassott, G., Dijkstra, T.K., \& Wilson, B. (2012). Analysing quadratic effects of formative constructs by means of variance-based structural equation modelling. European Journal of Information Systems, 21(1), 99-112. 
Hitt, M.A., Hoskisson, R.E., \& Kim, H. (1997). International diversification: Effects on innovation and firm performance in product-diversified firms. Academy of Management Journal, 40(4), 767-798.

Hoffmann, W.H. (2007). Strategies for managing a portfolio of alliances. Strategic Management Journal, 28(8), 827-856.

Huggins, R. (2010). Forms of network resource: Knowledge access and the role of inter-firm networks. International Journal of Management Reviews, 12(3), 335352.

Jarvis, C.B., MacKenzie, S.B., \& Podsakoff, P.M. (2003). A Critical Review of Construct Indicators and Measurement Model Misspecification in Marketing and Consumer Research. Journal of Consumer Research, 30(2), 199-218.

Jiang, R.J., Tao, Q.T., \& Santoro, M.D. (2010). Alliance portfolio diversity and firm performance. Strategic Management Journal, 31(10), 1136-1144.

Kale, P., Dyer, J., \& Singh, H. (2002). Value creation and success in strategic alliances: Alliancing skills and the role of alliance structure and systems. European Management Journal, 19(5), 463-471.

Kale, P., \& Singh, H. (2009). Managing Strategic Alliances: What Do We Know Now, and Where Do We Go From Here? Academy of Management Perspectives, 23(3), 45-62.

Kim, S. (2014). Influence of Firm and Partner Resources on Firm Performance in the Alliance Portfolio.M@n@gement, 17(2),88-109.

Kogut, B. (1988). Joint ventures: theoretical and empirical perspectives. Strategic Management Journal (1986-1998),9(4), 319-332.

Koka, B.R., \& Prescott, J.E. (2002). Strategic alliances as social capital: A multidimensional view. Strategic Management Journal, 23(9), 795-816.

Lahiri, N., \& Narayanan, S. (2013). Vertical integration, innovation, and alliance portfolio size: Implications for firm performance. Strategic Management Journal, 34(9), 1042-1064.

Lane, P.J., \& Lubatkin, M. (1998). Relative absorptive capacity and interorganizational learning. Strategic Management Journal, 19(5), 461-477.

Lavie, D. (2006). The Competitive Advantage of Interconnected Firms: an Extension of the Resource-Based View. Academy of Management Review, 31(3), 638-658.

Lavie, D. (2007). Alliance portfolios and firm performance: A study of value creation and appropriation in the U.S. software industry. Strategic Management Journal, 28(12), 1187-1212. 
Lavie, D. (2008). Network Resources: Toward a New Social Network Perspective. Academy of Management Review, 33(2), 546-550.

Lavie, D., \& Miller, S. R. (2008). Alliance Portfolio Internationalization and Firm Performance. Organization Science, 19(4), 623-646.

Lazzarini, S.G. (2007). The impact of membership in competing alliance constellations: Evidence on the operational performance of global airlines. Strategic Management Journal, 28(4), 345-367.

Lee, G.K. (2007). The significance of network resources in the race to enter emerging product markets: the convergence of telephony communications and computer networking, 1989-2001. Strategic Management Journal, 28(1), 17-37.

Lin, H. (2012). Cross-sector Alliances for Corporate Social Responsibility Partner Heterogeneity Moderates Environmental Strategy Outcomes. Journal of Business Ethics, 110(2), 219-229. http://doi.org/10.1007/s10551-012-1423-2

Milgrom, P., \& Roberts, J. (1990). The Economics of Modern Manufacturing: Technology, Strategy, and Organization. The American Economic Review, 80(3), 511-528.

Min, J., \& Mitsuhashi, H. (2012). Dynamics of unclosed triangles in alliance networks: disappearance of brokerage positions and performance consequences. Journal of Management Studies, 49(6), 1078-1108.

Mitsuhashi, H., \& Greve, H.R. (2009). A matching theory of alliance formation and organizational success: complementarity and compatibility. Academy of Management Journal, 52(5), 975-995.

Mu, J., Love, E., \& Peng, G. (2008). Interfirm networks, social capital, and knowledge flow. Journal of Knowledge Management, 12(4), 86-100.

Nieto, M.J., \& Santamaría, L. (2007). The importance of diverse collaborative networks for the novelty of product innovation. Technovation, 27(6-7), 367-377.

Park, B.J., Srivastava, M.K., \& Gnyawali, D.R. (2014). Impact of competition in the alliance portfolio and competition experience on firm innovation. Technology Analysis \& Strategic Management, 26(8), 893-907.

Parkhe, A. (1991). Interfirm diversity, organizational learning, and longevity in global strategic alliances. J. International Business Studies, 22(4), 579-601.

Petter, S., Straub, D.W . \& Rai, A. (2007). Specifying Formative Constructs in Information Systems Research. MIS Quarterly, 31(4), 623-656.

Phelps, R., Adams, R. J., \& Bessant, J. (2007). Life cycles of growing organizations: A review with implications for knowledge and learning. International Journal of Management Reviews, 9(1), 1-30. 
Reagans, R.E., \& Zuckerman, E.W. (2008). All in the family: Reply to Burt, Podolny, and van de Rijt, Ban, and Sarkar. Industrial and Corporate Change, 17(5), 979999.

Real, J. C., Roldán, J. L., \& Leal, A. (2014). From entrepreneurial orientation and learning orientation to business performance: Analysing the mediating role of organizational learning and the moderating effects of organizational size. British Journal of Management, 25(2), 186-208.

Reinartz, W., Haenlein, M., \& Henseler, J. (2009). An empirical comparison of the efficacy of covariance-based and variance-based SEM. International Journal of Research in Marketing, 26(4), 332-344.

Roberts, N., \& Thatcher, J. (2009). Conceptualizing and Testing Formative Constructs: Tutorial and Annotated Example. The Data Base for Advances in Information Systems, 40(3), 9-39.

Rogers, E.M. (1995). Diffusion of Innovations, New York, NY: The Free Press.

Rothaermel, F.T., \& Boeker, W. (2008). Old technology meets new technology: Complementarities, similarities, and alliance formation. Strategic Management Journal, 29(1), 47-77.

Sakakibara, M. (1997). Heterogeneity of firm capabilities and cooperative research and development: an empirical examination of motives. Strategic Management Journal (1986-1998), 18(Summer Special Issue), 143-164.

Sarkar, M., Aulakh, P.S., \& Madhok, A. (2009). Process Capabilities and Value Generation in Alliance Portfolios. Organization Science, 20(3), 583-600.

Shah, R.H., \& Swaminathan, V. (2008). Factors Influencing Partner Selection in Strategic Alliances: The Moderating Role of Alliance Context. Strategic Management Journal, 29(5), 471-494.

Shan, W., \& Hamilton, W. (1991). Country specific advantage and international cooperation. Strategic Management Journal (1986-1998), 12(6), 419-432.

Stuart, T.E. (2000). Interorganizational alliances and the performance of firms: A study of growth and innovation rates in a high-technology industry. Strategic Management Journal, 21(8), 791-811.

Vanhaverbeke, W., Gilsing, V., Beerkens, B., \& Duysters, G. (2009). The role of alliance network redundancy in the creation of core and non-core technologies. Journal of Management Studies, 46(2), 215-244.

Wassmer, U.F. (2010). Alliance portfolios: a review and research agenda. Journal of Management, 36(1), 141-171. 
Wassmer, U.F. (2007). Alliance portfolios and value creation: Theory and empirical evidence from the global airline industry. Universitat Ramon Llull. Retrieved from http://www.tesisenred.net/handle/10803/9188

Wassmer, U.F., \& Dussauge, P. (2012). Network resource stocks and flows: how do alliance portfolios affect the value of new alliance formations? Strategic Management Journal, 33(7), 871-883.

Williams, J., \& MacKinnon, D.P. (2008). Resampling and distribution of the product methods for testing indirect effects in complex models. Structural Equation Modeling, 15(1), 23-51.

Wuyts, S., Dutta, S., \& Stremersch, S. (2004). Portfolios of interfirm agreements in technology-intensive markets: Consequences for innovation and profitability. Journal of Marketing, 68(2), 88-100.

Zahra, S.A., \& George, G. (2002). Absorptive Capacity: a Review, Reconceptualization, and Extension. Academy of Management Review, 27(2), 185203.

Zheng, S., Li, H., \& Wu, X. (2013). Network resources and the innovation performance. Management Decision, 51(6), 1207-1224. 


\section{Appendix: Existing conceptualizations of divergence or difference in Alliance Portfolios}

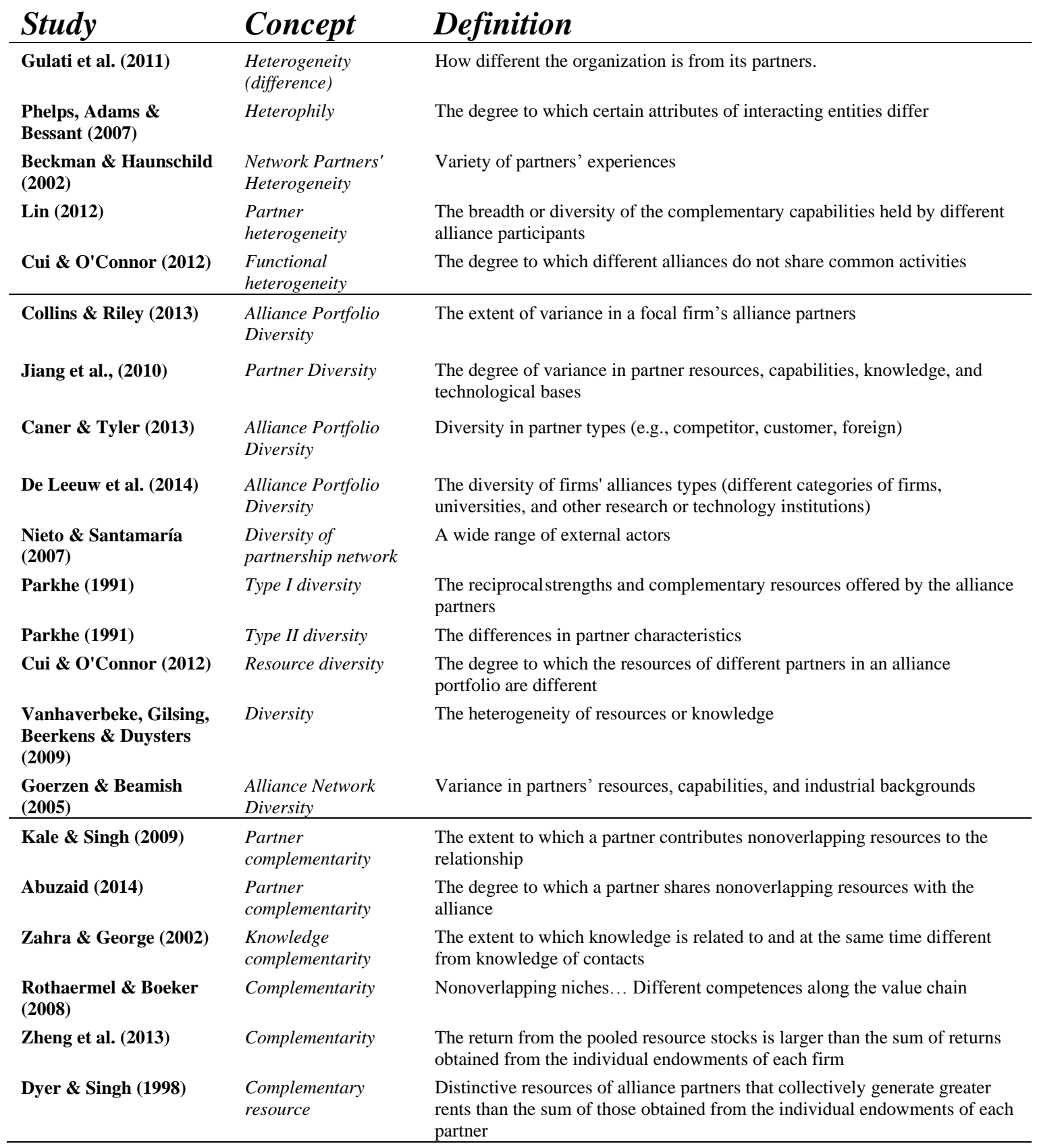

